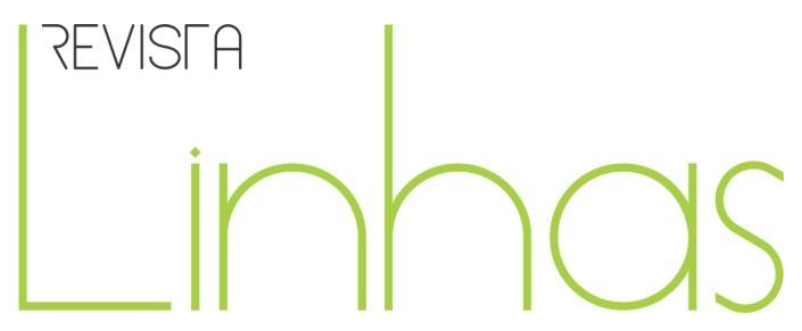

\title{
O ensino em sociologia como prática: diferenças e clivagens nos distintos espaços institucionais
}

\section{Resumo}

O debate sobre o ensino de sociologia tem sido ampliado nos últimos anos, especialmente após a reintrodução dessa disciplina no ensino médio a partir de 2008; entretanto, pouco tem sido discutido acerca do ensino de sociologia no ensino superior. Este artigo visa contribuir para a discussão analisando o ensino das disciplinas voltadas para a prática de ensino de ciências sociais/sociologia no ensino superior, especificamente junto a licenciaturas de ciências sociais. Analisamos os projetos pedagógicos de seis cursos de ciências sociais no país, localizados em diferentes regiões, utilizando como variável os cursos cujas práticas são lecionadas por professores vinculados aos departamentos de ciências sociais/sociologia, e aqueles que são lecionados por professores das faculdades de educação. Observou-se que o recorte institucional tem implicações sobre a forma como a sociologia é lecionada, havendo uma presença mais significativa de práticas pedagógicas quando estas se encontram vinculadas aos departamentos de ciências sociais/sociologia.

Palavras-chave: Ensino de sociologia. Prática de ensino em ciências sociais. Formação de professores de sociologia.

\author{
Amurabi Oliveira \\ Universidade Federal de Santa \\ Catarina - UFSC - Florianópolis/SC - \\ Brasil \\ amurabi_cs@hotmail.com \\ Rosimere Aquino da Silva \\ Universidade Federal do Rio Grande \\ do Sul - UFRGS - Porto Alegre/RS - \\ Brasil \\ rosimeriaquinodasilva@gmail.com

\section{Carolina Nascimento} \\ Universidade Federal de Santa \\ Catarina - UFSC - Florianópolis/SC - \\ Brasil \\ cah.castro@gmail.com
}

\section{Para citar este artigo:}

OLIVEIRA, Amurabi; SILVA, Rosimere Aquino da; NASCIMENTO, Carolina. O ensino em sociologia como prática: diferenças e clivagens nos distintos espaços institucionais. Revista Linhas. Florianópolis, v. 21, n. 45 , p. 183-204, jan./abr. 2020.

\section{DOI: $10.5965 / 1984723821452020183$}

http://dx.doi.org/10.5965/1984723821452020183 


\title{
The teaching of sociology as practice: differences and cleavages in the different institutional spaces
}

\begin{abstract}
The debate on the teaching of sociology has been expanded in recent years, especially after the reintroduction of sociology in high school since 2008, however, little has been discussed about the teaching of sociology in higher education. This article aims to contribute to the discussion by analyzing the teaching of disciplines focused on the practice of teaching social sciences/sociology in higher education, specifically with training courses of teachers in social sciences. We analyze the pedagogical projects of six social sciences courses in the country, located in different regions, using as a variable the courses whose practices are taught by professors linked to the departments of social sciences/sociology, and those that are taught by faculty of education. It was observed that the institutional cut has implications on the way in which sociology is taught, with a more significant presence of pedagogical practices when these are linked to the departments of social sciences/sociology.
\end{abstract}

Keywords: Teaching Sociology. Teaching practice in social sciences. Training of sociology teachers. 
A literatura que trata da história da sociologia no Brasil assume recorrentemente como marco inicial deste debate, a criação dos primeiros cursos de ciências sociais na década de $1930^{1}$ (MICELI, 1989), ainda que se reconheça a existência de cátedras anteriores nas escolas secundárias desde o final do século XIX (OLIVEIRA, 2013), bem como a circulação de ideias e teorias sociológicas em outros espaços, como no caso das Faculdades de Direito.

No bojo dessas questões é interessante notar que, em grande medida, naturalizamos a compreensão de ciências sociais que temos atualmente, o que restringe tais ciências à antropologia, à ciência política e à sociologia; no entanto, essa é uma compreensão que se consolida apenas na segunda metade do século $\mathrm{XX}$, havendo diferentes arranjos locais sobre o que seriam essas ciências. Um exemplo ilustrativo desse ponto é o fato de que o curso de ciências sociais da Universidade do Distrito Federal (UDF) possuía três diferentes menções: história, geografia e sociologia.

Neste sentido, quando nos voltamos para o debate sobre o ensino de sociologia no ensino superior, especificamente com relação à formação de quadros profissionais na sociologia, nos remetemos à tradição interdisciplinar de formação nos cursos de ciências sociais, nos quais se articulam a sociologia, a antropologia e a ciência política. Observa-se que temos como marco significativo para a melhor delimitação disciplinar nestes cursos, a Reforma Universitária de 1968, que consolida os quadros de pós-graduação no Brasil, sendo esse um ponto de inflexão relevante na medida em que no Brasil a formação disciplinar em sociologia concentra-se na pós-graduação, portanto, é a partir da pósgraduação que se clarificam os campos das chamadas ciências sociais.

É no contexto posterior à reforma de 1968 que se expandem numericamente os cursos de ciências sociais no Brasil (LIEDKE FILHO, 2005), o que demarca um caso bastante singular no contexto latino-americano, de incremento dessas formações em plena ditadura militar, o que se deu de forma concomitante à perseguição política de alguns dos mais destacados intelectuais do campo.

\footnotetext{
${ }^{1}$ Os primeiros cursos de ciências sociais criados no Brasil foram os da Escola Livre de Sociologia e Política de São Paulo (ELSP) em 1933, da Universidade de São Paulo (USP) em 1934, da Universidade do Distrito Federal (UDF) em 1935, da Faculdade de Filosofia, Ciências e Letras do Paraná, em 1938, e da Faculdade de Filosofia, Ciências e Letras da Bahia em 1941.
} 
Os cursos de graduação em ciências sociais, portanto, tornam-se os espaços de formação de sociólogos, antropólogos e cientistas políticos, ainda que possa ter havido outros modelos e variações pontuais nos quais também se formaram esses tipos de profissionais $^{2}$. Tendencialmente, tais cursos oferecem dois diferentes tipos de habilitações 3 : o bacharelado e a licenciatura, sendo que dentro da legislação atual apenas os bacharéis em ciências sociais podem ser considerados sociólogos ${ }^{4}$.

A estruturação dos cursos de ciências sociais segue uma lógica amplamente replicada em todo o país, com forte orientação teórica nos três eixos centrais de sua formação, além de disciplinas metodológicas e outras de caráter complementar remetendo a campos correlatos, como no caso da história, psicologia, economia etc. Quando se trata dos cursos de formação de professores, acrescentam-se ainda as disciplinas de caráter teórico no campo da educação, as didáticas e práticas pedagógicas, compreendidas como espaço de articulação entre a teoria e a prática na realidade escolar, cuja estruturação vem sendo sensivelmente alterada nos últimos anos, especialmente por meio de dispositivos legais do Conselho Nacional de Educação (CNE).

No presente artigo, nos voltaremos para a análise do ensino de sociologia na universidade, de forma mais específica na prática de ensino desta ciência. Para tanto, assumiremos como base de análise empírica os projetos pedagógicos de seis cursos de licenciatura em ciências sociais de diferentes regiões do Brasil, sendo que em três deles a prática de ensino é conduzida pelo departamento de ciências sociais/sociologia: Universidade de Brasília (UnB), Universidade Federal do Ceará (UFC) e Universidade Federal do Pará (UFPA); e em outros três pelas Faculdades de Educação: Universidade de São Paulo (USP), Universidade Federal do Rio de Janeiro (UFRJ) e Universidade Federal do Rio Grande do Sul (UFRGS). Para uma melhor compreensão por parte do leitor de nosso trabalho, iniciaremos com uma contextualização mais geral sobre os cursos de formação de professores de sociologia no Brasil.

\footnotetext{
${ }^{2}$ Dois exemplos ilustrativos dessas variações são os cursos de administração pública e sociologia e política, criados em 1952 na Faculdade de Ciências Econômicas de Minas Gerais, e ainda os cursos de história e geografia da Faculdade Catarinense de Filosofia, que possuíam como uma das áreas de concentração a antropologia cultural.

${ }^{3}$ Compreende-se atualmente que a licenciatura e o bacharelado constituem cursos autônomos e não habilitações do mesmo curso.

${ }^{4}$ Trata-se da lei $n^{\circ} 6.888$, de 10 de dezembro de 1980.
} 
Atenta-se ainda para o fato de que ao assumirmos como variável o lócus institucional no qual ocorre a docência de tais disciplinas, retomamos em certa medida a discussão acerca da divisão entre as Faculdades de Educação e os Departamentos de Ciências Sociais/Sociologia na produção de conhecimento na interface entre as ciências sociais e a educação. Ainda que possamos perceber diferenças metodológicas, epistemológicas e de caráter organizativo institucional entre tais espaços, escaparia do foco e do escopo deste artigo retomar essa discussão já bastante explorada na área (MARTINS; WEBER 2010; OLIVEIRA; SILVA, 2016; ALMEIDA; HEY, 2018).

\section{A formação de professores de sociologia no Brasil hoje}

Em princípio, o curso formador de professores de sociologia é, por excelência, a licenciatura em ciências sociais, mas é importante indicar a existência de outras possibilidades, como é o caso da licenciatura em ciências humanas com habilitação em sociologia ofertada em alguns campi da Universidade Federal do Maranhão (UFMA), ou ainda a habilitação a partir do terceiro ciclo de formação do bacharelado interdisciplinar em ciências humanas da Universidade da Integração Internacional da Lusofonia AfroBrasileira (UNILAB).

Mesmo em meio aos cursos de licenciatura em ciências sociais, há certa heterogeneidade em termos de formação, como nos indica Handfas (2009). Alguns cursos perduraram com a licenciatura como uma habilitação subsequente ao bacharelado, ou ainda como habilitação conjunta, modelo este que paulatinamente tem sido suplantado pela formação autônoma de ambos os cursos, o que se acelera com a Resolução CNE/CP n² 2, de $1^{\circ}$ de julho de 2015.

A heterogeneidade persiste em relação à carga horária, ainda que a legislação em vigor indique uma carga horária mínima (que passou a partir de 2015 de 2800 horas para 3200), observa-se que há cursos que ultrapassam a expectativa legal e outros que chegam a ofertar menos do que é demandado atualmente.

No caso específico da licenciatura, essa diversidade também reflete o processo recente de expansão no número de cursos, alavancado especialmente pela reintrodução da sociologia no currículo escolar, ainda que esse não seja um fator isolado, já que: 
[...] devemos considerar a confluência de outros fatores para compreendermos o que ocorreu, já que a volta da Sociologia à escola se deu no período de implantação do Programa de Apoio a Planos de Reestruturação e Expansão das Universidades Federais (REUNI), bem como de criação dos Institutos Federais, que passaram a atuar também na oferta de licenciaturas, não à toa, quatro dos novos cursos se vinculam a essas instituições, embora se trate de uma inserção ainda problemática na estrutura da rede de Educação Profissional e Tecnológica. (PANSARDI, 2013)

É válido rememorar que este cenário também possibilitou a criação de novos cursos de bacharelado, apesar de o crescimento não ter sido tão intenso. Cabe destacar que muitos dos novos cursos passaram a ofertar exclusivamente a habilitação da licenciatura; porém, em alguns casos, criaram-se inclusive bacharelados com um caráter mais disciplinar em Antropologia, Ciência Política e Sociologia ou, ainda, a partir de outros arranjos como Antropologia e Arqueologia, Ciência Política e Relações Internacionais, Ciência Política e Sociologia, o que aponta para outras possibilidades de diálogos intelectuais. (Oliveira, 2015, p. 52)

Este processo impactou não apenas os novos cursos, como também aqueles que já existiam e que demandaram uma nova reflexão sobre suas orientações a partir da nova realidade que estava sendo posta. A clássica “divisão de trabalho" entre as Faculdades de Educação e os Departamentos de Ciências Sociais/Sociologia passa a ser repensada e, em muitos casos, as disciplinas de prática de ensino passam a ser assumidas por esses departamentos, ou ainda, passa-se a demandar a contratação de professores especialistas nesse campo específico junto às Faculdades de Educação.

Outro dado importante de se considerar na análise dos cursos de formação de professores de sociologia no Brasil é sua concentração em Instituições de Ensino Superior (IES) públicas, mais especificamente em universidades públicas. Esse dado contraria a tendência mais geral que observamos no ensino superior brasileiro, que nas últimas décadas passou a contar com uma presença cada vez mais significativa de IES privadas, com predominância de instituições não universitárias (NEVES, 2002).

Focando de forma mais específica em nosso objeto de análise empírico, ainda que a legislação determine o quantitativo de horas da prática de ensino em cursos de licenciatura (400 horas), que deveria ser vivenciada a partir da metade do curso, podemos encontrar alguma variação tanto com relação à carga horária quanto ao momento no qual o estudante tem contato com essa parte do currículo, o que parece 
indicar diferentes concepções sobre como formar professores de sociologia, bem como sobre o lugar da prática nesse processo.

A prática de ensino na sociologia mostra-se como algo profundamente desafiador na medida em que não encontramos na disciplina um acúmulo solidificado de reflexões em torno de seu ensino, tanto na educação básica quanto na superior, em que pese o incremento da produção sobre o ensino de sociologia nos últimos anos (CAREGNATO; CORDEIRO, 2014; OLIVEIRA, 2016; BORDART; 2017; BODART; CIGALES, 2017; HANDFAS, 2017; OLIVEIRA, MELCHIORETTO, 2020).

Soma-se a isso a própria heterogeneidade formativa em termos teóricos que encontramos nos cursos de ciências sociais, como bem demonstra M. Oliveira (2015). No que diz respeito ao ensino de teorias sociológicas, há uma relativa homogeneidade no ensino das teorias clássicas, porém, o das teorias contemporâneas seria altamente diversificado, o que aponta para o fato de que sob o manto da denominação de "cursos de ciências sociais" encontramos uma realidade sensivelmente diversa.

De forma bastante sucinta, poderíamos afirmar que a rigor não há um consenso sobre o que se deva ensinar nos cursos de ciências sociais, o que se reflete nas disciplinas de prática de ensino. Um caminho que poderia "resolver" essa questão poderia ser a maior aproximação como currículo da educação básica, todavia, a tentativa de se estabelecer a Base Nacional Comum Curricular (BNCC), anseio que remete à década de 1980 (SILVA et al, 2015), esbarrou nos descaminhos políticos que o Brasil passou no período mais recente e no retrocesso das políticas educacionais.

Esta seção poderia ser resumida na afirmação da inexistência de modelos unificados para a formação de professores de sociologia no Brasil, ainda que haja orientações gerais que permaneçam, como a articulação entre a antropologia, a ciência política e a sociologia. No campo da prática de ensino (como poderemos observar com mais detalhes nas seções seguintes), essa questão se complexifica, ao tensionar não apenas “o que ensinar”, mas também “como ensinar”. 


\section{A prática de ensino nos Departamentos de Ciências Sociais/Sociologia}

Como indicado anteriormente, os cursos de ciências sociais surgem de uma proposta profundamente interdisciplinar mas que, ao mesmo tempo, buscava-se autonomizar o debate em relação ao campo jurídico, uma vez que os cursos de direito outorgavam o título de bacharéis em ciências jurídicas e sociais. Em que pese o período no qual a sociologia esteve presente compulsoriamente nos cursos complementares do ensino secundário, no intervalo compreendido entre a Reforma Campos, em 1931, e a Reforma Capanema, em 1942, é evidente que a discussão sobre formação docente esteve historicamente afastada da formação de cientistas sociais no Brasil, sendo retomada paulatinamente a partir do processo de redemocratização nos anos de 1980, e acelerando-se a partir de 2008, com a retomada da sociologia nos currículos do ensino médio de forma compulsória.

Ainda que não nos interesse aqui retomar o apanhado histórico sobre a presença da sociologia no currículo escolar, parece-nos válido realizar esse apontamento de modo a indicar que, historicamente, os departamentos de ciências sociais/sociologia tiveram um parco acúmulo de discussões acerca do ensino da sociologia no currículo escolar. Quando tais departamentos passam a se consolidar, já no contexto da Reforma Universitária de 1968, as licenciaturas em ciências sociais habilitavam seus egressos principalmente para o ensino de Organização Social e Política do Brasil (OSPB), disciplina criada em 1963 por iniciativa de Anísio Teixeira (1900-1971) ainda no governo de João Goulart (1919-1976), mas que perdurou nos currículos escolares até 1993, sendo notória sua apropriação pelo regime militar em termos de orientação ideológica que passa a assumir neste período histórico.

Tal contextualização é necessária para compreendermos as configurações que o ensino de sociologia no currículo escolar passa a assumir em diferentes IES, especialmente naquelas que possuem cursos criados em período anterior ao ano de 2008.

O curso de graduação em ciências sociais da Universidade de Brasília (UnB) foi fundado em 1969, a partir da criação do Departamento de Ciências Sociais. Atualmente, são disponibilizadas quatro habilitações para o estudante de graduação, ofertadas pelo 
Departamento de Sociologia e pelo Departamento de Antropologia. São elas: Ciências Sociais Bacharel, Ciências Sociais Licenciatura, Sociologia e Antropologia. O aluno que deseja cursar qualquer uma dessas habilitações entrará, primeiramente, pela opção de Ciências Sociais Bacharel e, somente após o terceiro semestre do curso, poderá escolher em qual das ramificações irá se habilitar, sendo possível se graduar em até duas opções. Só há a opção de curso diurno.

Em processo de reforma do curso de licenciatura, o novo currículo de ciências sociais da UnB entrou em vigor no segundo semestre de 2017. De acordo com as informações disponibilizadas no site da UnB, Matrícula Web (http://matriculaweb.unb.br), a Língua de Sinais Brasileira Básico foi a única disciplina obrigatória adicionada ao novo currículo. De forma extracurricular, no contexto de reformulação do curso surgem diversos projetos que contribuem e fortificam o seu espaço, como o Prodocência (2010); o Programa Institucional de Bolsas de Iniciação à Docência (PIBID), que está em vigor desde o edital 2013/CAPES; e em 2015, a criação do Laboratório de Ensino de Sociologia Lélia Gonzalez (LELIA) (SANTOS, 2002).

Porém, ainda assim, o atual currículo da licenciatura traz elementos do modelo tradicional $3+1$, em que três quartos do curso são dedicados a estudos de conhecimentos específicos da área (bacharelado) e um quarto é destinado aos estudos didáticopedagógicos. Ademais, a licenciatura continua sendo uma habilitação do curso de Ciências Sociais, e não um curso autônomo. O licenciando deve cursar um total de 168 créditos (2520 horas), sendo que desses, 60 créditos (900 horas) relativos a um tronco comum de todas as habilitações (bacharel) e 30 créditos (450 horas) relacionados à formação docente. Os demais 78 créditos (1170 horas) são reservados às disciplinas optativas.

As disciplinas obrigatórias exclusivas da Licenciatura são: Didática Fundamental (04 créditos - 60 horas); Fundamentos de Desenvolvimento e Aprendizagem (06 créditos - 90 horas); Organização da Educação Brasileira (04 créditos - 60 horas); Psicologia da Educação (04 créditos - 60 horas); Língua de Sinais Brasileira Básico (04 créditos - 60 horas); e Prática de Ensino de Ciências Sociais (08 créditos - 120 horas). Dessas disciplinas, apenas a última é ofertada pelo Departamento de Sociologia; as demais são distribuídas 
entre a Faculdade de Educação, o Departamento de Psicologia e o Departamento de Letras.

A ementa da disciplina Prática de Ensino em Ciências Sociais traz como objetivo a preparação do alunato para a profissão docente e propõe fazê-lo por meio de debates acerca de pesquisas sobre o ensino de sociologia e por discussões da vivência do estágio feito pelos licenciandos nas escolas de ensino médio. Além disso, o programa dispõe que:

A disciplina deve oferecer ao (à) estudante ferramentas para formulação de programa da disciplina de Sociologia na escola onde atuará como docente de segundo grau, definindo bibliografia básica, delimitando campo de estudo e conceitos fundamentais para ministrar um curso que forneça ao alunato do ensino médio instrumentos básicos para pensar sociologicamente. Em uma segunda frente, a disciplina Prática de Ensino visa a problematização dos diversos saberes circulantes no universo da docência na área das Ciências Sociais, oportunizando a inserção e convivência do professor-estagiário no contexto das instituições de Educação Básica. (UNIVERSIDADE DE BRASíLIA, 2019, s/p)

Leal (2017, p. 13), por meio de entrevistas com os licenciandos em ciências sociais da UnB no período de 2011 a 2014, conseguiu organizar repertórios de percepções acerca da sociologia no ensino médio e do próprio curso de licenciatura em ciências sociais da UnB. Uma das importantes contribuições da pesquisa foi dar voz aos alunos que sugeriram ações para melhoria do curso, dentre elas: "mais disciplinas específicas em Ciências Sociais ofertadas durante a habilitação pelo Departamento de Sociologia; mais prática de ensino e orientações para planejamento de aulas".

Concomitantemente à fundação do curso de Ciências Sociais da UnB, é criada, em 1969, a Faculdade de Ciências Sociais da Universidade Federal do Ceará (UFC). Em 1974, a Faculdade foi extinta e fundou-se o Departamento de Sociologia, que, em 2001, passa a ser chamado de Departamento de Ciências Sociais. Esse departamento administra os cursos de graduação em Antropologia, Sociologia e Ciência Política, nas modalidades bacharel e licenciatura.

A atual estrutura curricular da licenciatura em ciências sociais da UFC conta com as seguintes disciplinas obrigatórias e específicas a esta modalidade: Oficina de Ensino (07 créditos - 112 horas); Prática do Trabalho Docente I (06 créditos - 96 horas); Prática do 
Trabalho Docente II (06 créditos - 96 horas); Prática do Trabalho Docente III (06 créditos 96 horas); Prática do Trabalho Docente IV (07 créditos - 112 horas); Didática I (04 créditos 64 horas); Psicologia do Desenvolvimento e da Aprendizagem na Adolescência (04 créditos - 64 horas); Estrutura, Política e Gestão Educacional (04 créditos - 64 horas); Estudos Sócio-Históricos e Culturais da Educação (04 créditos - 64 horas); e Informática Aplicada ao Ensino (06 créditos - 96 horas). (UNIVERSIDADE FEDERAL DO CEARÁ, 2019).

Pode-se observar, assim, que as disciplinas de prática docente correspondem a um total de 25 créditos (400 horas), conforme orientado pela Resolução CNE/CP $n^{\circ} 2$, de $1^{\circ}$ de julho de 2015. Além dessas, outras seis disciplinas fazem parte do currículo da licenciatura em ciências sociais da UFC, somando um total de 54 créditos (864 horas) de matérias obrigatórias relativas ao ofício docente. As quatro disciplinas de Prática do Trabalho Docente e a Oficina de Ensino são oferecidas pelo Departamento de Ciências Sociais; as demais fazem parte do Departamento de Fundamentos da Educação.

Dentre os objetivos propostos pelas quatro disciplinas de práticas de ensino estão: oferecer o contato com a prática pedagógica das escolas; realizar o levantamento de dados e problematização do campo; estudar a aplicabilidade das Ciências Sociais na ação educativa; aprofundar a reflexão em torno do sentido da ação educativa passível de ser desenvolvida pelo cientista social; analisar criticamente o material didático; planejar as atividades docentes; identificar e analisar estratégias de ensino, natureza dos conteúdos e formas de avaliação; e, por fim, exercer a regência da sala de aula (UNIVERSIDADE FEDERAL DO CEARÁ, 2019).

Outra universidade em que a prática de ensino é localizada na Faculdade de Ciências Sociais é a Universidade Federal do Pará (UFPA). O curso de Ciências Sociais da UFPA foi fundado em 1954 na antiga Faculdade de Filosofia, Ciências e Letras do Pará, e consiste em um dos cursos pioneiros do Brasil. O currículo da licenciatura em Ciências Sociais é semelhante ao da UFC. A prática do trabalho docente também é realizada por meio de quatro disciplinas, em uma carga-horária total de 400 horas, a saber: Estágio Supervisionado I; II; II e IV. Cada disciplina possui 100 horas de aula e elas devem ser cursadas do quinto semestre do curso até o oitavo, respectivamente.

Segundo o Plano Político-Pedagógico (2011, p. 32) do curso, "a atividade de estágio supervisionado tem por intuito possibilitar ao discente contato com situações e espaços 
de atuação na prática do ensino em Ciências Sociais". E entre as competências e habilidades a serem desenvolvidas pelas disciplinas de Estágio Supervisionado estão:

Atuar no ambiente educacional promovendo o desenvolvimento de aprendizagem sobre conteúdos específicos as Ciências Sociais e suas relações com demais ares do saber; demonstrar compreensão sobre a necessidade de reflexão sobre a prática pedagógica para 0 aperfeiçoamento constante; trabalhar em equipe promovendo o diálogo entre as Ciências Sociais e as demais áreas do conhecimento; planejar, elaborar, analisar recursos didáticos e metodologias utilizadas no ensino das Ciências Sociais. (UNIVERSIDADE FEDERAL DO PARÁFPA, 2011, p. 67)

Algumas semelhanças e diferenças entre os cursos apresentados podem ser destacadas. As três universidades se aproximam pela tradição e consolidação dos cursos de Ciências Sociais, fundados entre as décadas de 1950 e 1960 do século passado. Todas oferecem habilitações tanto em bacharel (Sociologia e Antropologia) quanto em licenciatura (Ciências Sociais). Além disso, nas três universidades, a disciplina de práticas de ensino é ofertada pelo Departamento de Sociologia/Ciências Sociais.

Por outro lado, a estrutura dos currículos de licenciatura, bem como a distribuição dos conteúdos da prática de ensino, são feitas de forma diversa. Enquanto a UnB oferece apenas uma disciplina de prática, de oito créditos (120 horas), a UFC e a UFPA possuem quatro módulos da disciplina, ofertadas em quatro semestres, numa carga-horária total de 400 horas. Além disso, a UFC dispõe objetivamente, pelas ementas, a regência da sala de aula, enquanto a UnB e a UFC enfatizam a inserção e contato do licenciando com as instituições de nível básico, mas não explicitamente pela regência.

Podemos levantar como hipótese que a preocupação com um "forte" repertório preparatório para a atuação dos egressos da licenciatura relaciona-se principalmente a dois fatores: a) que os departamentos de ciências sociais/sociologia possuem uma preocupação mais diretamente conectada com a inserção profissional dos cientistas sociais, ainda que esta não seja uma preocupação predominante, dada a orientação acadêmica de tais cursos; b) que o ensino de sociologia no currículo escolar poderia ser pensado como uma espécie de "sociologia pública", e que, portanto, haveria alguma preocupação por parte desses departamentos em pensar a sociologia escolar como um 
lócus de difusão dos conhecimentos sociológicos para um público mais amplo, notadamente os estudantes do ensino médio.

\section{A prática de ensino nas Faculdades de Educação}

Retomamos aqui o marco fundamental que fora a Reforma Universitária de 1968, na qual as Faculdades de Educação são criadas. Para Cunha (1992), a criação de tal espaço institucional implicou num distanciamento da sociologia da pesquisa educacional, uma vez que nas Faculdades de Educação passou-se a concentrar tal debate. Podemos afirmar, portanto, que tal espaço institucional é composto, principalmente, por agentes especializados no campo educacional, o que leva a uma aproximação com um debate mais prático (CAREGNATO; CORDEIRO, 2014).

Em tais Faculdades é recorrente a existência de departamentos de didática e/ou metodologia de ensino, nos quais se acumula um substantivo debate sobre a formação de professores, e de modo mais específico acerca das práticas pedagógicas. Sendo assim, ainda que não haja em tais departamentos necessariamente um acúmulo de experiências com o ensino de sociologia, dada a descontinuidade no currículo escolar dessa disciplina, existe uma ampla discussão sobre metodologias de ensino, transposição didática etc.

Como um espelho invertido, poderíamos afirmar que ao passo que os departamentos de ciências sociais/sociologia possuem uma substancial discussão sobre os fundamentos teóricos da sociologia, porém, um parco conhecimento sobre sua dimensão pedagógica, nas Faculdades de Educação o debate sobre ensino de sociologia encontra seu principal substrato a partir das questões próprias do campo educacional, especialmente aquelas que se relacionam com a dimensão propriamente didática.

De acordo com informações disponíveis no site, a formação em Ciências Sociais da Universidade Federal do Rio de Janeiro (UFRJ) foi implantada no ano de 1939, no âmbito da antiga Faculdade Nacional de Filosofia da Universidade do Brasil. A graduação em Licenciatura em Ciências Sociais foi instituída no primeiro semestre de 2009. O curso é noturno e acolhe 60 alunos no primeiro semestre letivo do ano, egressos do sistema ENEM/SISU. Ele ainda oferta vagas em editais de transferência para alunos de outras universidades, para mudança de curso e para isenção de vestibular (graduados em 
qualquer universidade e qualquer curso). A implantação do curso de Licenciatura resultou de articulações entre os Departamentos de Antropologia Cultural e de Sociologia do Instituto de Filosofia e Ciências Humanas com a Faculdade de Educação da UFRJ. Dessa forma, o Projeto Pedagógico do curso objetiva uma integração entre os conteúdos curriculares específicos das Ciências Sociais e a formação pedagógica prestada pela Faculdade de Educação. O argumento é o de que essa articulação permite uma consistente formação em Ciências Sociais, nos moldes do Bacharelado, com capacitação para a pesquisa e a pós-graduação e para que os processos pedagógicos de ensinoaprendizagem sejam contemplados integralmente na formação do licenciado.

Para obter a diplomação, o aluno deverá cumprir 136 créditos, totalizando no mínimo 2890 horas. Na distribuição curricular do curso, é possível localizar dez disciplinas obrigatórias vinculadas diretamente ao campo educacional, distribuídas ao longo dos semestres/períodos. São elas: Educação Brasileira, Fundamentos Sociológicos Educação, Filosofia Educação - Mundo Ocidental, Profissão Docente, Didática, Psicologia da Educação, Didática Ciências Sociais I, Prática de Ensino Ciências Sociais-Estágio Supervisionado, Didática Ciências Sociais II. A disciplina de Libras (Educação e Comunicação) também compõe esse rol; ela é ofertada na Faculdade de Educação. A disciplina Prática de Ensino Ciências Sociais - Estágio Supervisionado tem uma carga horária de 400 horas práticas. De acordo com a ementa, busca a capacitação do licenciando como profissional, objetiva o reconhecimento de instituições, projetos e experiências de desenvolvimento curricular nos espaços educativos. Assim, são realizadas a observação e a análise de experiências docentes, em escolas de educação básica e desenvolvidas práticas pedagógicas, reflexivas, críticas e criativas (UNIVERSIDADE FEDERAL DO RIO DE JANEIRO, 2020).

Cabe ressaltar que, no terceiro período do curso, são ofertadas pelos departamentos de Antropologia Cultural e de Sociologia do Instituto de Filosofia e Ciências Humanas, três disciplinas para a Licenciatura em Ciências Sociais: Prática de questões antropológicas contemporâneas, Prática de questões sociológicas contemporâneas e Prática de questões contemporâneas de ciências políticas. De acordo com suas ementas, elas objetivam compreender atividades práticas, contextualizadas nas referidas disciplinas e seus conteúdos, voltadas especialmente para o desenvolvimento 
docente e a produção de subsídios pedagógicos e de materiais didáticos ao ensino das Ciências Sociais.

Na Universidade de São Paulo (USP), o Bacharelado é requisito para a conclusão da Licenciatura. A Faculdade de Filosofia, Letras e Ciências Humanas foi fundada em 25 de janeiro de 1934 com o nome de Faculdade de Filosofia, Ciências e Letras (FFCL). Idealizada como o polo central da Universidade de São Paulo (USP), destinava-se à formação de pesquisadores em diversas áreas do conhecimento, abrangendo as áreas de ciências exatas, humanas e biológicas. Atualmente, a Faculdade de Filosofia, Letras e Ciências Humanas - mais conhecida como FFLCH - oferece cinco cursos de graduação: Ciências Sociais, Filosofia, Geografia, História e Letras, acolhendo 1.669 novos alunos por ano.

O site informa que o curso de graduação em Ciências Sociais está estruturado em torno de três campos de conhecimento teórico e metodológico, formados pelos Departamentos de Sociologia, Antropologia e Ciência Política, que formam o núcleo do curso juntamente com Metodologia e Técnicas de Pesquisa. Com essa estruturação modular do Curso de Ciências Sociais, espera-se que o cientista e/ou profissional da área disponha de formação teórica e de pesquisa que o habilite a desenvolver sua capacidade analítico-crítica; ter domínio das principais correntes de pensamento e das obras e autores que construíram as Ciências Sociais do século XVIII até a atualidade; ter o domínio dos principais conceitos teóricos e metodológicos por meio dos quais possam ser identificados e analisados os problemas sociais, culturais, econômicos, políticos, etnográficos etc. da sociedade moderna.

O estudante se forma como bacharel e deverá cumprir no mínimo 155 créditos, totalizando 2550 horas. Para obter diploma de Licenciatura é necessário cursar disciplinas na Faculdade de Educação, e no próprio curso, relacionadas à formação de professores. A licenciatura estrutura-se, portanto, pela formação do bacharel complementada pelas disciplinas pedagógicas. Com essa finalidade, o aluno deverá cursar, de forma obrigatória, as disciplinas de Língua Brasileira de Sinais, Metodologia do Ensino I, Metodologia do Ensino, Didática, Política e Organização da Educação Básica no Brasil. Também são elencadas disciplinas eletivas. Além de cursar essas disciplinas, cumprir 400 horas de 
estágio, distribuídas em 300 horas na Faculdade de Educação + 100 horas na disciplina de Estágio Supervisionado para as Ciências Sociais (UNIVERSIDADE DE SÃO PAULO, 2020).

Conforme o programa da disciplina, O Estágio Supervisionado para as Ciências Sociais busca desenvolver habilidades para a docência no ensino médio e a qualificação do futuro professor de Ciências Sociais. Dessa forma, são realizadas atividades práticas e projetos na área de ensino e de educação, tais como produção de conteúdos e estratégias didáticas voltadas à disciplina de Sociologia no ensino médio e como recurso auxiliar ao trabalho do professor da rede pública de ensino, assim como o desenvolvimento de pesquisa na área de ensino de sociologia ou de educação. Na Faculdade de Educação, a seção de Estágios (onde o licenciando deve cumprir as 300 horas) atende e orienta os alunos e professores sobre as normas que regem os estágios obrigatórios e outros. Os professores responsáveis atuam fundamentalmente na articulação da universidade com escolas públicas para realização dos estágios e no acompanhamento dos estágios curriculares supervisionados. Além disso, são organizados eventos voltados para o estágio tais como o Encontro de Orientações Gerais sobre Estágio e a Mostra de Estágios.

Na Universidade Federal do Rio Grande do Sul (UFRGS), ao ingressar no curso de Ciências Sociais, o aluno escolhe uma habilitação: licenciatura, que o habilita a lecionar no ensino médio, ou bacharelado, que privilegia sua preparação para a pesquisa, a pósgraduação e a docência no Ensino Superior. Depois de formado em uma habilitação, ele pode prosseguir seus estudos na outra, e, assim, obter habilitação nas duas. A soma da carga horária das disciplinas da Licenciatura, obrigatórias e eletivas, assim como dos créditos complementares, resulta em 2745 horas. Créditos obrigatórios, eletivos e complementares, totalizam 183.

Na segunda etapa do curso, são disponibilizadas as disciplinas de Organização da Escola Básica e Psicologia da Educação I. Libras na terceira etapa, assim como, de forma alternativa, História da Educação: história da escolarização brasileira e processos pedagógicos, Mídia e tecnologias digitais em espaços escolares, Pesquisa em educação I. Na quarta etapa, o currículo oferece ao aluno Educação contemporânea: currículo, didática, planejamento, Estudos de sociologia da educação e Psicologia da Educação II. Políticas da Educação Básica e Teorias do currículo são disponibilizadas como disciplinas 
alternativas. Na sexta etapa, as disciplinas de Ensino e Identidade Docente, de Intervenção pedagógica e necessidades educativas especiais e de Sociologia no Ensino Médio - Teoria e Prática, figuram como obrigatórias. Na sétima e oitava etapas do curso, também são ofertadas (sucessivamente) as disciplinas de Estágio de Docência em Ciências Sociais I e Estágio de Docência em Ciências Sociais II. Essas últimas disciplinas totalizam 405 horas. Para cursá-las, são pré-requisitos ter cursado disciplinas obrigatórias, disponíveis no currículo, oferecidas em etapas anteriores. Por último, o aluno deverá elaborar um Trabalho de Conclusão de Curso - Licenciatura Ciências Sociais. (UNIVERSIDADE FEDERAL DO RIO GRANDE DO SUL, 2020).

As súmulas dos Estágios de Docência I e II, dessa universidade, esclarecem que essa etapa do curso objetiva a inserção e a convivência do discente-estagiário no contexto escolar, a partir de sua atuação como regente/docente de sala de aula na área de Ciências Sociais/Sociologia em instituições de Educação Básica. É uma atividade de ensino de caráter teórico-prático, na qual ocorre a elaboração de um Plano de Trabalho, bem como a problematização do objeto de ensino das Ciências Sociais, da escola como espaço sociocultural, das identidades dos sujeitos implicados com os processos de ensino e aprendizagem, com as temáticas, as metodologias, o currículo e o planejamento didático-pedagógico, a partir de uma postura investigativa, analítica e reflexiva.

Podemos observar, portanto, que as atividades desenvolvidas nas Faculdades de Educação encontram-se articuladas a outras disciplinas com caráter "teórico-prático", de modo que o diálogo é desenvolvido a partir de um escopo mais amplo da discussão sobre formação de professores. Poderíamos mesmo inferir que a discussão sobre a prática se encontra relativamente residual nesse espaço institucional. Esse caráter pode ter relação com a heterogeneidade formativa do corpo docente de tais Faculdades, uma vez que ao agregar as diferentes práticas pedagógicas de suas respectivas instituições, as Faculdades de Educação passam a contar com um número limitado de docentes especializados em cada campo disciplinar.

Ademais, devemos considerar que a ausência de um vínculo direto entre as Faculdades de Educação e as coordenações de curso de ciências sociais, implica que o direcionamento do desenho curricular, assim como do perfil profissional fica a cargo de outra Faculdade, separando uma discussão entre formação profissional e a elaboração de 
diretrizes para esta formação, ainda que seus professores possuam eventualmente assentos nos colegiados e nos núcleos docentes estruturantes das licenciaturas em ciências sociais. Esse desenho representa ainda, em última instância, as disputas próprias existentes entre as Faculdades no campo acadêmico, que envolvem principalmente elementos "extra-acadêmicos" (BOURDIEU, 2011).

\section{Considerações finais}

Dentro da proposta deste breve artigo, pudemos analisar panoramicamente como ocorre o ensino das práticas pedagógicas em ciências sociais, voltadas para a formação de professores de sociologia. Em outros termos, nos voltamos para como, no ensino superior, a sociologia é ensinada visando à docência na educação básica, o que assumiu como fio condutor a análise das diferenças entre essas práticas nas Faculdades de Educação e nos Departamentos de Ciências Sociais/Sociologia.

Observamos que as práticas alocadas institucionalmente junto aos departamentos de ciências sociais/sociologia ocupavam um espaço significativo na formação docente, ultrapassando recorrentemente o mínimo exigido pelos documentos legais (400 horas de práticas e 400 horas de estágio), o que pode ser fruto do fato de que aqueles departamentos que optam por assumir as práticas pedagógicas na sociologia são também aqueles nos quais há uma preocupação mais forte com a formação de professores. Apesar de nossa amostra possuir uma forte dimensão qualitativa, ao elegermos universidades consolidadas de diferentes regiões do país, ela não nos possibilita generalizar nossos achados para outras realidades de forma simples, uma vez que a expansão recente das licenciaturas de ciências sociais criou também diferentes modelos formativos.

Por outro lado, nas Faculdades de Educação encontramos as práticas de ensino de ciências sociais mais "isoladas", o que pode refletir a divisão institucional existente. As demandas nas Faculdades de Educação são múltiplas, o que implica também na existência de um corpo docente bastante heterogêneo, normalmente composto por alguns poucos docentes responsáveis pelas práticas de determinadas áreas do conhecimento, como as ciências sociais, a matemática, a biologia, as artes etc. 
Ressalta-se aqui um elemento importante, que não foi analisado neste artigo por fugir de seu escopo: os professores responsáveis pelas práticas de ensino em ciências sociais nas Faculdades de Educação normalmente possuem sua formação inicial no campo das ciências sociais, havendo maior diversidade com relação a sua formação pósgraduada, recorrentemente realizada no campo da educação, ao passo que nos Departamentos de Ciências Sociais/Sociologia ocorre o inverso; a maior convergência em termos de formação se dá no nível doutoral. Isso pode implicar na produção de disposições sociais distintas, que por sua vez implicam diretamente sobre a concepção de ensino de sociologia que tais profissionais possuem. Essa também é uma agenda de pesquisa ainda em aberto que mereceria maior atenção por parte dos pesquisadores do tema.

Longe de nos centrarmos aqui em uma crítica a determinados modelos formativos, o que nos interessa é demonstrar como o ensino da sociologia se vincula não apenas aos conteúdos, ou mesmo aos agentes, como também às estruturas institucionais nos quais ele ocorre. O comparativo entre as disciplinas que possuem o mesmo caráter e a mesma finalidade, porém situadas em espaços institucionais distintos, nos chama a atenção para como a organização pedagógica de determinada disciplina acadêmica se vincula também a sua filiação institucional. Ainda que não seja possível aprofundar neste artigo, tais conclusões nos abrem uma ampla agenda investigativa acerca dos elementos que modelam a prática pedagógica, nas mais distintas disciplinas e não apenas na sociologia.

Por fim, cabe reconhecer que o significativo avanço das discussões sobre o ensino de sociologia na educação básica realizadas na última década em especial, não foi acompanhado por discussões na mesma intensidade sobre o ensino de sociologia no ensino superior, nem ao menos no que diz respeito aos cursos de formação de professores de sociologia. Dada a heterogeneidade do ensino superior brasileiro, e do sistema universitário em especial, a análise das práticas de ensino de sociologia no ensino superior demanda um exame cuidadoso, que reconheça ao mesmo tempo as diretrizes gerais do ensino dessa ciência e dos cursos de formação nos quais ela é lecionada, mas, ao mesmo tempo, visibilize também os aspectos idiossincráticos que o ensino de sociologia assumirá nos diferentes arranjos locais. 


\section{Referências}

ALMEIDA, Ana Maria F.; HEY, Ana Paula. Sociologia da educação: olhares sobre um campo em ascensão. In: MICELI; S.; MARTINS, C. B. (orgs.). Sociologia brasileira hoje. São Paulo: Ateliê Editorial, 2018. p. 253-310.

BODART, Cristiano. Configurações do ensino de sociologia como um subcampo de pesquisa: análise dos dossiês publicados em periódicos acadêmicos. Revista Ciências Sociais Unisinos, Porto Alegre, v. 53, n. 3, p. 453-557, set/dez, 2017.

BODART, Cristiano; CIGALES, Marcelo. Ensino de sociologia no Brasil (1993-2015): um estado da arte na pós-graduação. Revista de Ciências Sociais, Fortaleza, v.48, n. 2, p.256281, jul./dez., 2017.

BOURDIEU, Pierre. Homo academicus. Florianópolis: EDUFSC, 2011.

CAREGNATO, Célia E.; CORDEIRO, Victória C. Campo científico-acadêmico e a disciplina de sociologia na escola. Educação \& Realidade, Porto Alegre, v. 39, n. 1, p. 39-57, jan./mar. 2014.

CUNHA, Luiz Antônio. A educação na sociologia: um objeto rejeitado? Cadernos Cedes, Campinas, n. 27, p. 9-22, 1992.

HANDFAS, Anita. A Formação do Professor de Sociologia. In: HANDFAS, Anita; OLIVEIRA, Luiz Fernandes. (org.). A sociologia vai à escola: história, ensino e docência. Rio de Janeiro: Quartet, 2009.

HANDFAS, Anita. As pesquisas sobre o ensino de sociologia na educação básica. In: SILVA, Ileizi; GONÇALVES, Danyelle N. Sociologia na educação básica. São Paulo: Annablume, 2017. p. 367-385.

LIEDKE FILHO, Enno D. A sociologia no Brasil: história, teorias e desafios. Sociologias, Porto Alegre, v. 7, n. 14, p. 376-436, jul./dez., 2005.

LEAL, Sayonra. Dispositivos de normatização do ensino de sociologia na escola: formação e saberes docentes de licenciandos em ciências sociais no distrito federal. Educ. Soc., Campinas, v. 38, n. 141, p.1075-1099, out/dez,2017.

MARTINS, Carlos Benedito; WEBER, Silke. Sociologia da educação: democratização e cidadania. In: MARTINS, Carlos Benedito; MARTINS, Heloisa H. T. de S. (orgs.). Sociologia. São Paulo: Anpocs, 2010. p. 475-496.

MICELI, Sérgio. Condicionantes do desenvolvimento das Ciências Sociais. In: MICELI, Sérgio (org.). História das ciências sociais no Brasil: vol. 1. São Paulo: Editora Vértice: Idesp: Finep, 1989. p. 72-110. 
NEVES, Clarissa E. B. A estrutura e o funcionamento do ensino superior no Brasil. In: Soares, Maria S. A. (org.). A educação superior no Brasil. Brasília: Fundação Coordenação de Aperfeiçoamento de Pessoal de Nível Superior, 2002, p. 43-69.

OLIVEIRA, Amurabi. Cenários, tendências e desafios na formação de professores de ciências sociais no Brasil. Política \& Sociedade, Florianópolis, v. 14, n. 31, p. 38-61, set./dez., 2015.

OLIVEIRA, Amurabi. O ensino de sociologia na educação básica brasileira: uma análise da produção do GT ensino de sociologia na SBS. Revista Teoria e Cultura, Juiz de Fora, v. 11, n. 1, p. 55-70, jan./jun., 2016.

OLIVEIRA, Amurabi. Revisitando a história do ensino de Sociologia na Educação Básica.

Acta Scientiarum. Education, Maringá, v. 35, n. 2, p. 179-189, jul./dez., 2013.

OLIVEIRA, Amurabi; MELCHIORETTO, Beatriz. O ensino de sociologia como tema de pesquisa na agenda das ciências sociais brasileiras. BIB. Revista Brasileira de Informação Bibliográfica em Ciências Sociais, São Paulo, n. 91, p. 1-26, fev., 2020.

OLIVEIRA, Amurabi.; SILVA, Camila F. A sociologia, os sociólogos e a educação no Brasil. Revista Brasileira de Ciências Sociais, São Paulo, v. 31, n. 91, p. 1-15, jun, 2016.

OLIVEIRA, Márcio. O ensino da teoria sociológica em alguns cursos de Ciências Sociais de universidades públicas brasileiras. Política \& Sociedade, Florianópolis, v. 14, n. 31, p. 87 113, set./dez., 2015.

SANTOS, Mário B. O PIBID na área de ciências sociais: da formação do Sociólogo à formação do professor em Sociologia. 2017. Tese (Doutorado em Sociologia) Universidade de Brasília, Brasília, 2017.

SILVA, Ileizi L. F.; ALVES NETO, Henrique F.; VICENTE, Daniel V. A proposta da base nacional comum curricular e o debate entre 1988 e 2015. Revista Ciências Sociais Unisinos, Porto Alegre, v. 51, n. 3, p. 330-342, set./dez., 2015.

UNIVERSIDADE FEDERAL DO CEARÁ. Disciplinas ministradas (ementário). 2019.

Disponível em: http://www.cienciassociais.ufc.br/wp-

content/uploads/2017/04/ementario.pdf . Acesso em: 25 fev. 2019.

UNIVERSIDADE FEDERAL DO PARÁ. Projeto Político-Pedagógico do curso de Licenciatura em Ciências Sociais da UFPA. 2011. Disponível em:

http://www.fcs.ufpa.br/PPC\%20\%20LICENCIATURA\%20CIENCIAS\%20SOCIAIS\%20UFPA\%202 012.pdf. Acesso em: 14 fev. 2020.

UNIVERSIDADE FEDERAL DO RIO DE JANEIRO. Licenciatura em Ciências Sociais, currículo. 2020. Disponível em:

https://www.siga.ufrj.br/sira/temas/zire/frameConsultas.jsp?mainPage=/repositoriocurriculo/3D4B7267-92A4-F79A-oFD2-EC59DFF85A6C.html . Acesso em: 5 mar. 2020. 
UNIVERSIDADE FEDERAL DO RIO GRANDE DO SUL. Ciências Sociais, Licenciatura, Currículo. 2020. Disponível em:

http://www.ufrgs.br/ufrgs/ensino/graduacao/cursos/exibeCurso?cod_curso=312 . Acesso em: 5 mar. 2020.

UNIVERSIDADE DE BRASÍLIA. Programa da disciplina Prática de Ensino em Ciências Sociais. 2019. Disponível em:

https://matriculaweb.unb.br/graduacao/disciplina.aspx?cod=134627. Acesso em: 25 fev. 2019.

UNIVERSIDADE DE SÃO PAULO. Licenciatura em ciências sociais, currículo. 2020. Disponível em:

https://uspdigital.usp.br/jupiterweb/listarGradeCurricular?codcg=8\&codcur=8040\&codha $b=200$ \&tipo $=\mathrm{N}$. Acesso em: 5 mar. 2020.

Recebido em: 06/03/2020 Aprovado em: 15/03/2020

Universidade do Estado de Santa Catarina - UDESC Programa de Pós-Graduação em Educação - PPGE Revista Linhas

Volume 21 - Número 45 - Ano 2020 revistalinhas@gmail.com 